\title{
PANORAMA HISTÓRICO DAS METODOLOGIAS DE JOGOS TEATRAIS E JOGOS DRAMÁTICOS
}

\section{RESUMEN HISTÓRICO DE JUEGOS TEATOLÓGICOS Y METODOLOGÍAS DE JUEGOS DRAMÁTICOS}

Cintia Miranda dos SANTOS $^{1}$ Marcos Roberto Morali MARIN ${ }^{2}$ Braz PINTO JUNIOR ${ }^{3}$

\begin{abstract}
Resumo: O contexto lúdico que envolve a educação em artes, principalmente na linguagem teatral, trás para a criança a possibilidade de vislumbrar e vivenciar descobertas sociais e culturais híbridas, promovendo a troca de experiências e o respeito. Assim, o objetivo dessa pesquisa teórica é relatar a criação dos jogos teatrais e dos jogos dramáticos, além de discutir como estes podem ser utilizados em sala de aula para promover o ensino das metodologias de teatro, integrado com outras linguagens da Arte, a fim de experimentar e expandir diferentes possibilidades para o ensino/aprendizagem e o desenvolvimento do indivíduo. Para isto foi realizada uma pesquisa teórica em livros, dissertações e artigos científicos que trazem informações sobre a metodologia de Viola Spolin, Peter Slade e sobre o ensino de teatro. Como resultados conseguimos desenvolver um panorama histórico da criação dos jogos teatrais e jogos dramáticos, além de elucidarmos a sua utilização na educação infantil. A partir disso, verificamos a importância da educação integrada e participativa dos alunos, que gera oportunidades para a criança experienciar situações que possibilitam a construção de diferentes conhecimentos e de desenvolver várias habilidades, como expressão verbal, gestual, corporal, criatividade, intuição, espontaneidade e interação social.
\end{abstract}

Palavras-chave: Viola Spolin. Peter Slade. Educação infantil.

Resumen: El contexto lúdico que involucra la educación en las artes, principalmente en el lenguaje teatral, brinda al niño la posibilidad de vislumbrar y experimentar descubrimientos híbridos sociales y culturales, promoviendo el intercambio de experiencias y el respeto. Así, el objetivo de esta investigación teórica es dar a conocer la creación de juegos teatrales y juegos dramáticos, además de discutir cómo se pueden utilizar en el aula para promover la enseñanza de metodologías teatrales, integradas con otros lenguajes del Arte, con el fin de Experimentar y expandir diferentes posibilidades para la enseñanza / aprendizaje y el desarrollo del individuo. Para ello, se realizó una investigación teórica en libros, disertaciones

\footnotetext{
${ }^{1}$ Acadêmica do Curso de Artes Cênicas da UFGD. E-mail: sntos.miranda@gmail.com

${ }^{2}$ Acadêmico do Curso de Artes Cênicas da UFGD. E-mail: marin.vox@gmail.com.

${ }^{3}$ Docente da Faculdade de Comunicação Artes e Letras da UFGD. E-mail: BrazJunior@ufgd.edu.br
} 


\section{MORIZONTES - REVISTA DE EDUCAÇÃO}

e-ISSN: 2318-1540

y artículos científicos que aportan información sobre la metodología de Viola Spolin, Peter Slade y sobre la enseñanza del teatro. Como resultado, pudimos desarrollar un panorama histórico de la creación de juegos teatrales y juegos dramáticos, además de dilucidar su uso en la educación infantil. A partir de esto, verificamos la importancia de la educación integral y participativa de los estudiantes, que genere oportunidades para que el niño experimente situaciones que permitan la construcción de diferentes saberes y desarrolle diversas habilidades, como la expresión verbal, gestual, corporal, la creatividad, la intuición, la espontaneidad y interacción social.

Palabras-clave: Viola Spolin. Peter Slade. Educación Infantil.

\section{Introdução}

A experimentação com a arte desenvolve habilidades pessoais e sociais no indivíduo, dessa forma, Lloyd (2017) afirma que o envolvimento de crianças e adolescentes com as diferentes formas de arte, como música e teatro, melhora o autoconceito, a motivação, empatia, criatividade, imaginação, desinibição, entre outros benefícios, que promovem uma melhoria das competências cognitivas, sociais e individuais.

Assim, verificamos a importância da disciplina de Arte no Currículo escolar, de modo que a área de Arte envolve quatro linguagens artísticas, as Artes Visuais, a Música, o Teatro e a Dança. Sendo necessário, desenvolver atividades variadas que incorporem e combinem essas diferentes linguagens aplicadas no ensino dessa disciplina (BRASIL, 1998).

Dentre as linguagens que compõem a disciplina de Arte, destacamos o Teatro, que pode ser um instrumento para promover o desenvolvimento do indivíduo como um todo, despertando o gosto pela leitura, promovendo a socialização, cooperação em grupo, respeito ao próximo, disciplina, e, principalmente, melhorando a aprendizagem (CABRAL, 2006; SLADE, 1978).

Das diversas metodologias que podem ser utilizadas no teatro, com reflexões na sociologia, antropologia, práticas sociais e relações humanas, como métodos de Bertold Brecht, Stanislavski, Peter Brook, dentre outros, existe o Jogo Dramático de Peter Slade, que promove atividades orientadas, que dão oportunidade à criança de vivenciar situações que possibilitam a construção do conhecimento e o desenvolvimento de uma expressão ampla, verbal, gestual e criadora. Juntamente a isso, o Jogo Teatral de Viola Spolin é método para atores e também para o ensino de teatro para crianças, no qual a maioria dos jogos é altamente 


\section{MORIZONTES - REVISTA DE EDUCAÇÃO}

e-ISSN: 2318-1540

social e propõe um problema que deve ser solucionado - um ponto objetivo com o qual cada indivíduo se envolve e interage na busca de atingi-lo. Muitas habilidades aprendidas por meio do jogo são sociais (SPOLIN, 2010).

O método de Slade consiste em uma atividade de grupo, sendo possível criar espontaneamente através da imaginação e intuição. No qual, as crianças realizam brincadeiras que promovem seu desenvolvimento físico, emocional e o envolvimento social (DESGRANGES, 2006).

Enquanto o Jogo Teatral compõe-se em jogos que buscam solucionar algum problema em que os jogadores recebem instruções e a partir disso podem agir espontaneamente e utilizar o improviso para jogarem. Assim, neste método existem jogos específicos, com objetivos claros e a maioria tem um foco, instruções e avaliações para serem seguidos pelo orientador e pelos jogadores (SPOLIN, 2010).

Assim, verificamos como os jogos teatrais podem ser utilizados em sala de aula, seja para promover o ensino das metodologias de teatro, ou integrado com outra linguagem, como as Artes Visuais, para experimentar diferentes possibilidades para o ensino de Arte, esperando que dessa forma seja estimulado o interesse dos alunos em participar das aulas, visando promover um melhor ensino-aprendizagem dos conteúdos de forma prática e lúdica (DESIDERIO, 2013).

\section{Abordagem metodológica}

Este estudo consistiu em uma pesquisa teórica utilizando livros, dissertações e artigos científicos que trazem informações sobre a metodologia de Jogos Teatrais da Viola Spolin, do Jogo dramático de Peter Slade, sobre o ensino de teatro e também sobre outros autores e pesquisadores do teatro que de alguma maneira contribuíram para o desenvolvimento das metodologias de jogos teatrais e jogos dramáticos.

\section{Panorama histórico da concepção dos Jogos Teatrais de Viola Spolin e os Jogos Dramáticos de Peter Slade}




\section{MORIZONTES - REVISTA DE EDUCAÇÃO}

A primeira concepção de método dramático foi realizada por Caldwell Cook, um educador britânico conhecido por seu livro The Play Way publicado em 1917, que afirmava que "fazer" era um melhor método de aprendizado do que ler e ouvir, e que os jovens estudavam através de brincadeiras. $\mathrm{O}$ autor foi conduzido pelas ideias filosóficas e educacionais de Jean-Jacques Rousseau e de Jean Piaget (COURTNEY, 1980). Assim, de acordo Yoda (2010), que estudou a aplicação do método teatral de Courtney The Play Way como uma forma de auxiliar o ensino de Inglês no Japão, os alunos podem viver diversas experiências com os jogos, através de discussões e também ações dentro de um grupo. Nesse trabalho os alunos podem adaptar histórias, realizar encenações, improvisar seus figurinos e escrever diálogos. Enquanto, os professores devem interagir o mínimo possível para deixar que aflore no indivíduo a espontaneidade e autonomia.

Além disso, Piaget ao elaborar sua teoria do desenvolvimento cognitivo, demonstrou a importância da formação do símbolo na criança (PIAGET, 1975).

As conclusões de Piaget de que o símbolo (jogo dramático infantil) fazia parte das estratégias naturais do sujeito para assimilar a realidade e de que também se constituía num momento intermediário entre o exercício (atividade sensório-motora que antecede a emergência da função simbólica) e a regra (jogos compartilhados por mais de um indivíduo e regidos por regras explícitas, estabelecidas de comum acordo) tiveram grande repercussão no terreno terapêutico e pedagógico, contribuindo decisivamente para a conquista do espaço do jogo dramático (faz-de-conta) e das atividades com a linguagem teatral tanto na educação escolar da criança quanto na psicoterapia infantil (JAPIASSU, 2001, p.32).

Para Piaget a criança utiliza do jogo simbólico para compreender a realidade quando ela ainda não possui uma estrutura mental completamente desenvolvida. Assim, ela utiliza da imaginação e cria histórias fictícias de acordo com o que ela deseja para assimilar as informações e compreender os signos. Posteriormente ela irá passar para a fase de operatório concreto e operatório formal. Assim, verificamos a importância do jogo no desenvolvimento da criança.

Além dos estudos de Piaget, temos o pesquisador Jacob Levy Moreno, um psiquiatra que nasceu em 1889, em Bucareste e estudava a espontaneidade no teatro (DIAS, 2015). Em suas as pesquisas acabou descobrindo a função terapêutica do teatro. Após a realização de experimentos para determinar o funcionamento psicológico humano, ele propôs a terapia 


\section{MORIZONTES - REVISTA DE EDUCAÇÃO}

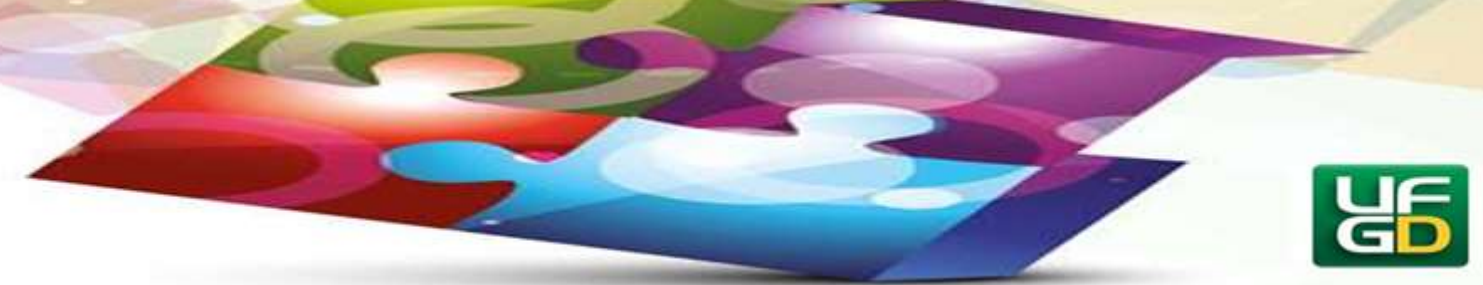

psicodramática, junto a isso estabeleceu dois procedimentos psicoterapêuticos, o psicodrama e o sociodrama. O primeiro explora as relações interpessoais e individuais, enquanto o segundo estuda as relações intergrupais, com base nas questões socioculturais (JAPIASSU, 2001).

Assim, por volta de 1926 o pedagogo e teatrólogo Peter Slade começa a pensar no drama para ser utilizado como terapia, com o auxílio de conselhos especializados. Posteriormente, passa a realizar experiências de 1931 a 1941, com o aconselhamento médico (SLADE, 1978). A partir disso, desenvolve uma metodologia para educação infantil usando o jogo dramático e lança em 1950 seu livro Child Drama, no qual recomenda uma série de exercícios e atividades dramáticas que visam estimular a criatividade, a livre-expressão e o desenvolvimento total dos indivíduos (JAPIASSU, 2001).

Segundo Slade, "O jogo dramático é uma parte vital da vida do jovem. Não é uma atividade de ócio, mas antes a maneira da criança pensar, comprovar, relaxar, trabalhar, lembrar, ousar, experimentar, criar e absorver. O jogo é na verdade a vida." (SLADE, 1978, p. 17-18).

Dessa forma para Slade:

[...] a introdução de métodos simples de jogo dramático no currículo escolar normal, traria um desenvolvimento feliz e natural, com um considerável efeito equilibrador sobre o caráter, a formação da confiança em si mesmo, e a melhoria do rendimento escolar e na aquisição do gosto em geral (SLADE, 1978, p. 101).

Slade (1978) acreditava que a melhor forma da criança se desenvolver tanto intelectualmente quanto fisicamente seria através de jogos. Pois, além de ser uma atividade prazerosa e vital para a vida, ela auxilia na formação do indivíduo e consequentemente melhora a aprendizagem.

De maneira diferente da abordagem do drama por Peter Slade, Viola Spolin criou um sistema de ensino de teatro através de jogos teatrais, no qual ela foi pioneira, realizando pesquisas por quase três décadas, com pessoas de todas as faixas etárias. Assim, estabelece um sistema tanto para o treinamento de atores quanto para a compreensão da comunicação não verbal e a dinâmica em grupo. Pois com estes jogos as pessoas têm interações entre elas, aplicando técnicas do teatro, como atuação e encenação, e assim podem utilizar uma linguagem corporal para expressarem-se e comunicarem-se (JAPIASSU, 2001). 


\section{MORIZONTES - REVISTA DE EDUCAÇÃO}

Para Spolin, qualquer um pode atuar e improvisar, desde que haja esforço para aprender e que o ambiente em que a pessoa está inserida favoreça a experiência criativa. Para que isso ocorra é necessário um envolvimento intelectual, físico e intuitivo com o ambiente e as situações criadas. Dessa forma, pode surgir a espontaneidade momentânea, sendo possível agir de forma livre e orgânica, e expressar-se verdadeiramente (SPOLIN, 2010).

Para a concepção de seu sistema de Jogos teatrais, Spolin inspirou-se nas atividades desenvolvidas por Neva Leona Boyd, uma professora com quem trabalhou de 1924 até 1927. Segundo Boyd o jogo era a oportunidade para promover a educação social de crianças e jovens. Pois, os jogos em grupos estimulavam a empatia, a cooperação, o esforço e a determinação. Mas, estes podiam ser individuais ou coletivos. Para Boyd o valor do jogo, está no próprio ato de jogar, os participantes tomam decisões espontâneas e não planejadas, e apenas seguir as regras do jogo (CAMARGO, 2002).

Flavio Desgranges (2006) em seu livro A pedagogia do teatro: provocação e dialogismo desenvolve uma análise crítica do sistema de Jogos Teatrais de Viola Spolin e questiona a pouca atenção dada a uma abordagem crítica dos aspectos político-sociais que surgem no desenvolver das criações dos participantes nos jogos. $\mathrm{O}$ autor explica que a avaliação de cenas é guiada pelo foco de investigação definido pelo exercício proposto, fazendo com que o participante se concentre na execução da ação e apreensão do aspecto proposto. Em contrapartida revela que em escritos de Viola Spolin ela deixa claro sua preocupação com a formação crítica do participante, "tendo em vista que isso pode dar-se pela ampliação da percepção do mundo e da sua possibilidade de atuação efetiva na vida social" (DESGRANGES, 2006, p. 118). Em suma: "o sentido da descoberta visa não apenas à criação de realidade no palco, mas implica a transposição do processo de aprendizagem para a estrutura total do indivíduo" (DESGRANGES, 2006, p 118 apud KOUDELA, 1984, p. 65).

Desgranges (2006) acrescenta que uma falta de estímulo, de questionamento crítico dos fatos que surgem nos exercícios propostos extravia possibilidades de intepretação de episódios sociais contidos nos mesmos e que cabe ao coordenador "se lhe parecer pertinente, indicar esta possibilidade de análise, estimulando o grupo para a relevância deste olhar. Bem como motivar os jogadores para o caráter crítico de suas realizações cênicas, que é o outro lado da mesma moeda" (DESGRANGES, 2006, p. 119). 


\section{MORIZONTES - REVISTA DE EDUCAÇÃO}

O autor afirma que o foco do exercício tem o objetivo de não ocasionar que os comentários das cenas fiquem vagos ou extremamente pessoais, não criando frutos para a avaliação, sendo a proposta do foco uma técnica que pretende centrar os comentários dos participantes aparentando o processo progressivo e cumulativo:

O foco, assim, não pode ser compreendido de uma perspectiva ditatorial, mas tomado com necessária flexibilidade. O coordenador do processo talvez precise estar atento às questões levantadas pelos jogadores que não digam respeito ao foco em questão, e que sugiram uma abordagem crítico-reflexiva das situações apresentadas em cena, que podem tratar tanto de aspectos do grupo e de cada jogador no âmbito da participação no próprio processo de investigação, ou de aspectos temáticos que surjam nas cenas (Ibid p. 119120).

Outra crítica apontada pelo autor Flavio Desgranges (2006) é sobre o tornar real a cena no sistema de Viola Spolin, que pode conduzir o participante a linguagem de imitar a realidade e não recriá-la. Acrescenta que isso não invalida a relevância do exercício, mas que é possível apresentar outro apontamento estilístico e fica a critério do coordenador desenvolver objetivos e esclarecer as escolhas feitas no processo, podendo até adaptar novos procedimentos, pois "ao mesmo tempo em que Spolin apresenta um sistema que pretende regular e abranger a atividade teatral, ele existe para ser superado e negado enquanto conjunto de regras" (KOUDELA, 1984, p. 47 apud DESGRANGES, 2006, p. 121).

\section{A utilização do Jogo Teatral e do Jogo Dramático na educação infantil}

A partir do exposto, verificamos que existem diferenças entre o Jogo dramático de Peter Slade e o Jogo Teatral de Viola Spolin. Na metodologia de Slade o foco é o desenvolvimento físico e emocional do indivíduo, através da realização de atividades lúdicas (SLADE, 1978). Enquanto o sistema de Spolin é voltado para o treinamento de atores atuarem no palco e estimular a espontaneidade das crianças e jovens. Onde existe um foco, instruções e avaliação (SPOLIN, 2010).

A abordagem anglo-saxônica do drama destaca exclusivamente os aspectos instrumentais da educação dramática, ao passo que o sistema de jogos teatrais de Viola Spolin, sem prejuízo de sua eventual utilização instrumental, permite, sobretudo reivindicar o espaço do teatro como 


\section{HORIZONTES - REVISTA DE EDUCAÇÃO}

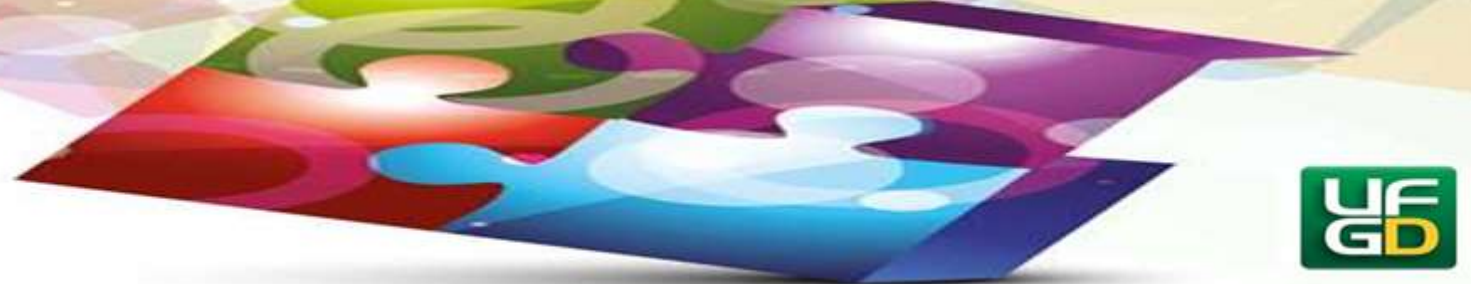

conteúdo relevante em si na formação do educando (JAPIASSU, 2001, p. $42)$.

Ambas as metodologias podem ser aplicadas em sala de aula, para promover o improviso, a liberdade pessoal, o trabalho de grupo, a socialização, e para estimular o ensino/aprendizagem. Mas devemos entender que existem diferenças entre a ação teatral e a ação dramática.

Teatro significa uma ocasião de entretenimento ordenada e uma experiência emocional compartilhada; há atores e públicos, diferenciados. Mas a criança, enquanto ainda ilibada, não sente tal diferenciação [...] drama no seu sentido original, da palavra grega drao - "eu faço, eu luto". No drama, i.e., no fazer e no lutar, a criança descobre a vida e a si mesma através de tentativas emocionais e físicas e depois através da prática repetitiva, que é o jogo dramático (SLADE, 1978, p. 18).

Porém, não se devem separar as técnicas teatrais do contexto dramático, pois o envolvimento emocional, muito utilizado nos jogos dramáticos deve ser mantido, caso contrário o potencial educacional do teatro perde-se (CABRAL, 2006).

Assim, ao trabalhar com a metodologia dos jogos é importante aplicar seus princípios de modo a beneficiar o aprendizado dos alunos, adequando-os ao tema a ser abordado quanto à forma de utilização dos jogos.

$\mathrm{Na}$ metodologia de Peter Slade as atividades a serem realizadas envolvem o uso de sons, músicas e objetos diferenciados, que podem ser utilizados para produzir sons e histórias criadas pelos próprios alunos para envolvê-los nos jogos dramáticos (SLADE, 1978).

Enquanto no sistema de Spolin utilizam-se jogos previamente definidos, nos quais existem três pontos principais: o foco, que é o problema técnico a ser resolvido; as instruções que são orientações fornecidas aos jogadores; e a avaliação que é forma de verificar se os jogadores conseguiram resolver o problema técnico. Como por exemplo, a ficha A3 "Ouvindo o Ambiente" do livro Jogos Teatrais: o fichário de Viola Spolin, na qual o Foco é “Ouvir o maior número de sons possível no ambiente” (SPOLIN, 2014). As instruções são “Ouça todos os sons à sua volta - até os mais imperceptíveis! Preste atenção! Ouça o maior número de sons possível” (Ibid, 2014). Por fim a avaliação é "Quais sons Você ouviu? (Peça 


\section{MORIZONTES - REVISTA DE EDUCAÇÃO}

e-ISSN: 2318-1540

para os jogadores identificarem tantos sons quanto possível) Quantos ouviram aquele som?

Quais sons ainda não foram mencionados?” (Ibid, 2014).

A partir da utilização destes jogos, será estimulada a espontaneidade, além de serem trabalhados aspectos específicos que são desejados na atuação. Dentre eles destacamos a Aprovação/Desaprovação, Expressão de grupo e Fiscalização (SPOLIN, 2010).

Na busca pela Aprovação/Desaprovação ocorre a perda de liberdade pessoal, quando há a necessidade de nossas ações serem aprovadas ou o medo da rejeição. Assim, é importante estimular a sensação de liberdade no processo criativo, a partir disso será possível adquirir a autoconsciência e a autoexpressão (SPOLIN, 2010).

O teatro é uma atividade que envolve muitas pessoas, assim a Expressão de grupo é importante, pois é necessária a interação intensa entre elas. Nela os alunos podem interagir com outros indivíduos e aprender com eles. Além disso, podem entender na prática a importância de fornecer espaço para que o outro tenha o seu momento de atuar, de se expressar, de ter a atenção das outras pessoas. Mas, nesta interação de grupo não deve existir competições, pois o objetivo final é que todos participem, aprendam e experienciem, não sendo positiva a competição, pois isto pode levar os jogadores a buscarem um "premio" no final, que seria a vitória (SPOLIN, 2010).

A Fisicalização representa a forma pela qual o material é apresentado no nível físico e sensorial. Representando assim a forma como o ator irá se comunicar com a plateia, para conseguir expressar o que deseja (SPOLIN, 2010).

\section{Considerações Finais}

A partir da pesquisa realizada verificamos a importância da educação lúdica e mais orgânica, que permite a experimentação e espontaneidade dos alunos. Assim, dentro da disciplina de Artes, é possível explorar outros campos do conhecimento e diferentes metodologias para aplicar os conteúdos obrigatórios do currículo escolar, de modo que as aulas possam despertar o interesse e a participação dos alunos nas atividades propostas.

Infelizmente o ensino em sala de aula vem sistematicamente apresentando a falta de interesse dos alunos e sua consequente não participação ou valorização dos conteúdos. Este é 


\section{MORIZONTES - REVISTA DE EDUCAÇÃO}

e-ISSN: 2318-1540

um paradigma que a educação moderna vem enfrentando há décadas e o intuito do desenvolvimento do ensino/aprendizagem através dos jogos teatrais e do jogo dramático é justamente criar uma perspectiva mais humana, que promova a equidade social, juntamente com a educação em direitos humanos, para que as crianças e jovens tenham consciência dos conflitos da vida cotidiana, para assim estarem preparados para o convívio social.

\section{Referências}

BRASIL. SECRETARIA DE EDUCAÇÃO FUNDAMENTAL. Parâmetros curriculares nacionais: arte / Secretaria de Educação Fundamental. - Brasília : MEC / SEF, 1998. 116 p.

CABRAL, BEATRIZ ANGELA VIEIRA. Drama como método de ensino. São Paulo: Hucitec/Mandacaru, 2006.

CAMARGO, ROBSON CORREA DE. Neva Leona Boyd e Viola Spolin - jogos teatrais e seus paradigmas. In: Sala Preta (USP), v. 2, São Paulo, 2002.

COURTNEY, RICHARD. Jogo, teatro e pensamento: As bases intelectuais do teatro na educação. São Paulo: Perspectiva, 1980.

DESGRANGES, FLAVIO. A pedagogia do teatro:provocação e dialogismo. São Paulo: Editora Hucitec: Edições Mandacaru, 2006.

DESGRANGES, FLÁVIO. O jogo dramático e a construção do discurso. In: . A pedagogia do teatro: provocação e dialogismo. São Paulo: Hucitec: Edições Mandacaru, 2006.

DESIDERIO, ADRIANA MARIA de OLIVEIRA. A importância e as contribuições da arte na interdisciplinaridade. In: Desafios para a docência em arte: teoria e prática. São Paulo: Universidade Estadual Paulista: Núcleo de Educação a Distância, 2013. 110 p.

DIAS, PAULA. Jacob Levy Moreno (1889 - 1974). Knoow.net Enciclopédia temática. Jun. 2015. Disponível em: <http://knoow.net/ciencsociaishuman/psicologia/jacob-levy-moreno/>. Acesso em: 09 jun. 2019.

JAPIASSU, RICARDO OTTONI VAZ. Metodologia do ensino de teatro. São Paulo: Papirus, 2001.

JAPIASSU, RICARDO OTTONI VAZ. Piaget-Slade X Elkonin-Vigotskii - Órbitas narrativas em rota de colisão: Faz de conta. Ação ativista do Observatório do desenvolvimento cultural vinculado ao Grupo de Estudos e Pesquisas em Atividade, Desenvolvimento Cultural, Educação Continuada e à Distância/GEPADEad. Vera Cruz - Bahia, 14 nov. 2011. Disponível

SANTOS, Cintia Miranda dos; MARIN, Marcos Roberto Morali; PINTO JUNIOR, Braz. PANORAMA HISTÓRICO DAS METODOLOGIAS DE JOGOS TEATRAIS E JOGOS DRAMÁTICOS Horizontes - Revista de Educação, Dourados-MS, v. 9, n. 05, 2020 


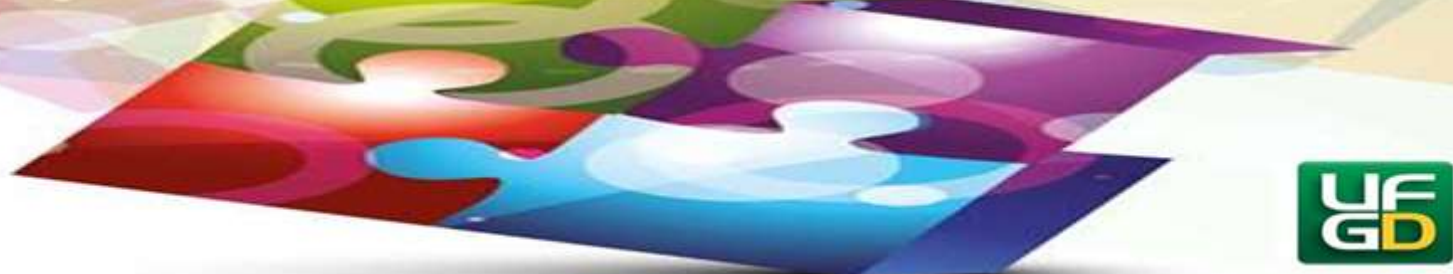

em: <http://observecult.blogspot.com/2011/11/piaget-slade-x-elkonin-vigotskii.html>. Acesso em: 10 jun. 2019.

LLOYD, KIMBERLY. Benefits of Art Education: A Review of the Literature. Scholarship and Engagement in Education. v. 1. 2017.

PIAGET, JEAN. A formação do símbolo na criança. Imitação, jogo e sonho, imagem e representação. 2. ed. Rio de Janeiro: Jorge Zahar, 1975.

SLADE, PETER. O jogo dramático infantil. Tradução de Tatiana Belinky. Direção de edição Fanny Abramovich. São Paulo: Summus. v.2. 1978.

SPOLIN, VIOLA. Improvisação para o teatro. Tradução e revisão Ingrid Dormien Koudela e Eduardo José de Almeida Amos. São Paulo: Perspectiva, 2010.

SPOLIN, VIOLA. Jogos Teatrais: o fichário de Viola Spolin. Tradução Ingrid Dormien Koudela. São Paulo: Perspectiva, 2014.

YODA, MANAMI. Henry Caldwell Cook's "Play Way" in Language Education. Human and Environmental Studies, v.19, p.79- 92, 2010.

Enviado: $30 / 06 / 2020$

Aceito: 31/08/2020 